\title{
Influence of regional features of psycho- emotional state of the Russian society on road accidents severity
}

\author{
Artur Petrov ${ }^{1, *}$ and Sergey Evtyukov ${ }^{2}$ and Daria Petrova ${ }^{3}$ \\ ${ }^{1}$ Tyumen Industrial University, Melnikaite street, 72-221, Tyumen, Russian Federation \\ ${ }^{2}$ Saint Petersburg State University of Architecture and Civil Engineering, 2 Krasnoarmeiskaya St. 4, \\ St. Petersburg, Russia \\ ${ }^{3}$ Federal University named after the first President of Russia B.N. Yeltsin, Ekaterinburg, Chapaev \\ street, 16a-511, Ekaterinburg, Russia
}

\begin{abstract}
The article considers issues of assessment of the relation between road accidents severity and psychoemotional state of Russian society. In the context of the hypothesis about the significant impact of people's awareness of the value of life on their ordinary behavior, four subtasks were solved. Firstly, the difference in road accidents severity between all road accidents and road accidents that happened in alcohol intoxication state was established. Secondly, indicators of the psychoemotional state of people from different Russian regions were identified. Thirdly, dependencies «Road accidents severity = $\mathrm{f}($ Psychoemotional state of people from Russian region)» for two cases «All road accidents» and «Road accidents that happened in alcohol intoxication state» were defined. Finally, it was found that degree of impact of alcohol intoxication on road accidents severity depends on the psychoemotional state of people from different Russian regions. Produced results can be used in the development of regional programs of road safety management taking into account features of the psychoemotional background in different subjects of Russia.
\end{abstract}

\section{Introduction and problem statement}

Russian Federation is the biggest $\left(17125191 \mathrm{~km}^{2}\right)$ and unique for the number of different nations (more than 190) country. The wide range of climatic and socio-economic conditions of people's lives in the whole country is a determining factor in the formation of serious heterogeneity of their lives quality [1,2]. People's quality of life is an abstract concept; however, researchers have made attempts to quantitively evaluate it [2]. And we can use these assessments in the solution of applied problems, including problems of the road safety sphere. Regarding the different characteristics of road accident rate, the ratio between leader-regions and outsider-regions can significantly differ [1]. For example, severity

Corresponding author: ArtIgPetrov@yandex.ru 
(percentage (in \%) of deaths from the number of victims) of all road accidents that took place in 2016 in the Republic of Ingushetia was 20.4, while in the St. Petersburg this indicator was 3.2 .

How significant is the impact of quality of life and psychoemotional state of people from different regions on the formation of such heterogeneous results in the road safety provision sphere? The answer to this important question can be used in the refinement of regional programs for road safety improvement. The article includes the results of research in the sphere of the establishment regularities of the impact of regional features of Russian society's psychoemotional state on the road accidents severity.

\section{Method of the problem solution}

During the solution of the problem of establishing the impact of Russian society's psychoemotional state on road accidents severity the method of regression analysis was used. Also, model «Road accidents Severity $=f$ (the indicator of the psychoemotional state of Russian regions' population)» for cases «All road accidents» and «Road accidents that happened in the alcohol intoxication state» was identified.

\subsection{The method of assessing the psychoemotional state of people from Russian regions}

The first attempt of evaluating the psychoemotional state of Russian society was made by scientists from Institute of Psychology of Russian Academy of Sciences [3, 4]. They developed a complex index of society's macropsychological state $[3,4]$ that was used for assessing the All-Russian dynamics of people's psychoemotional sphere.

However differentiated measurements of this indicator for all Russian regions were not made. With the advent of Big Data technology solution of the problem of assessment society's psychoemotional state became possible due to the Internet and social networks.

Since 2013 company Brand Analytics [5] have monitored for social networks with the aim of quantitative assessing of social networks users emotional state in all Russian regions [6]. Their technology based on the Big Data analyzed mentioning of words connected with categories of «love» and «hatred» that were written in the first person in the present time (e.g. positive: «I love», «I'm happy»; and negative: «I hate», «I'm annoyed»).

Index of social health or in other words Index of love is represented by Brand Analytics [5] as the ratio between Positive messages and Negative messages:

$$
\text { Index of Love }=\frac{\text { Number of Positive Messagesin Social Networks }}{\text { Number of Negative Messagesin Social Networks }}
$$

The last data of psychoemotional background in Russian regions were collected and analyzed in May of 2016 [6]. We will take this data as the basis of indicator «Psychoemotional state of region's population».

\subsection{The method of assessment road accidents severity in Russian regions}

Road accidents severity was assessed by statistical data of The General Administration for Traffic Safety of the Ministry of Internal Affairs of Russia [7]. The data was divided into two categories: «All road accidents» and «Road accidents that happened in the alcohol intoxication state». It is necessary for detection of the significant impact of alcohol on 
aggravation of road accidents severity without regard to the prevailing emotional background of the region.

\section{Theoretical premises of problem solution}

It is worth noting that the authorities of Russian Federation are interested in the issues of evaluation the society's psychoemotional state. In this regard specialists in the spheres of psychology, sociology and political science investigated this question [8, 9]. Foreign authors have actively investigated the issue of the influence of drivers' psychoemotional state on the possibility of road accident [10, 11, 12]. Among Russian authors who are actively engaged in the problem of the drivers' psychic reactions in the extreme situation, it is worth to highlight P. A. Pegin $[13,14,15]$. Acquaintance with the works of these authors was the stimulus of the research, results of which are considered in this article.

\section{Solution of the problem and results}

\subsection{Ranking of subjects of Russian Federation by the indicator Road accidents severity}

Analysis of the data of The General Administration for Traffic Safety of the Ministry of Internal Affairs of Russia on the road accident rate in regions allowed building ranked diagrams of distribution of Russian subjects by the indicator Road accidents severity (fig. 1...2). Analysis of these diagrams allows making preliminary conclusions:

- Russian regions significantly differ by the indicator Road accidents severity (in 2016 this difference reached more than 6 times for all road accident cases).

- The severity of road accidents that happened in the alcohol intoxication state increases by one and a half times relatively to the severity of road accidents in the case «All road accidents» and varies in the range from 7,7 (Murmansk Oblast) to 31,1 (The Republic of Adygea). The difference of this indicator reached up to 4 times. The only exception is Chukotka Autonomous Okrug where the value of Road accidents severity equals 0 .

\subsection{Ranking of subjects of Russian Federation by the indicator of psychoemotional state of regions' population.}

The analysis carried out by the author $[6,8,9]$ showed that in modern conditions researchers of psychoemotional background have a new tool - the technology of Big Data that allows working with giant information sets. In the context of this research analytical materials of company Brand Analytics were used [6]. Fig. 3 shows the ranked diagram of distribution of subjects of Russian Federation by the value of Index of social health (Index of love). As of summer of 2016, there was a serious difference in the psychoemotional state of population between Russian regions. This psychoemotional background is defined by different aspects of the life, including attitude to the value of life and, consequently, transport behavior. 


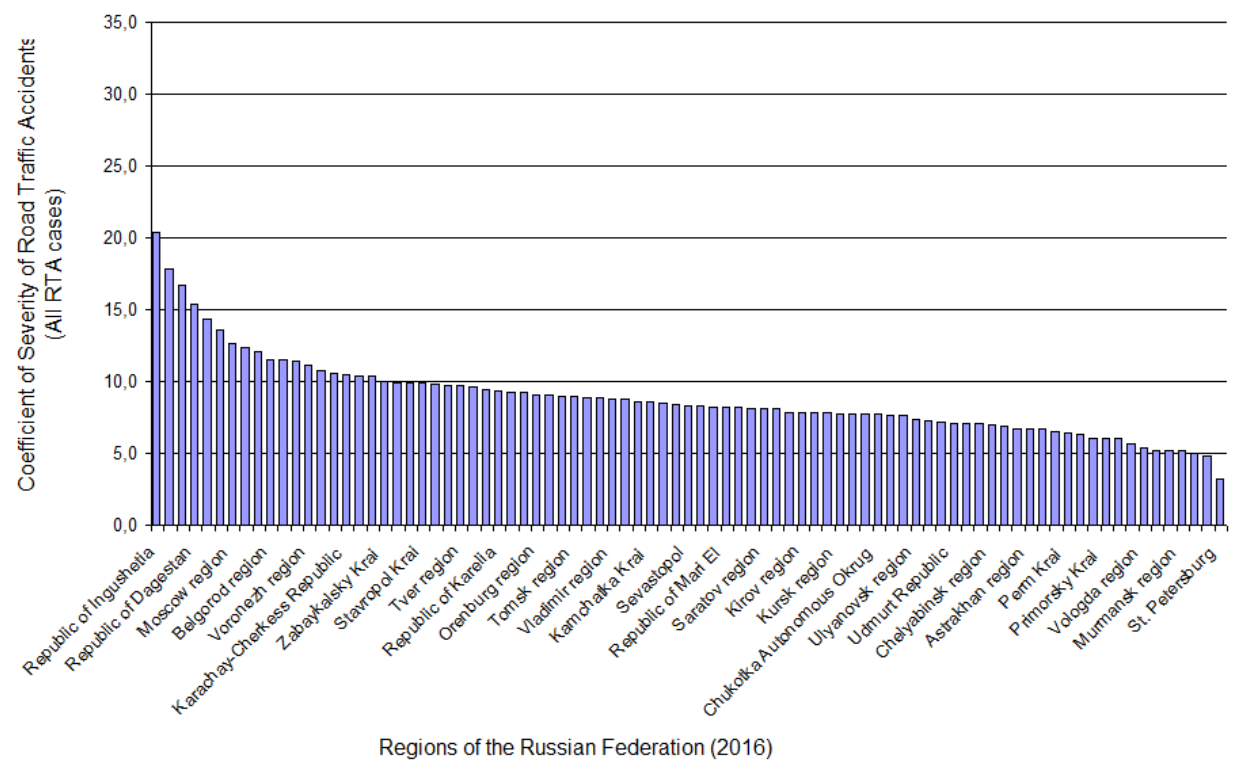

Fig. 1. Road accidents severity (all road accidents) in different regions of Russian Federation in 2016

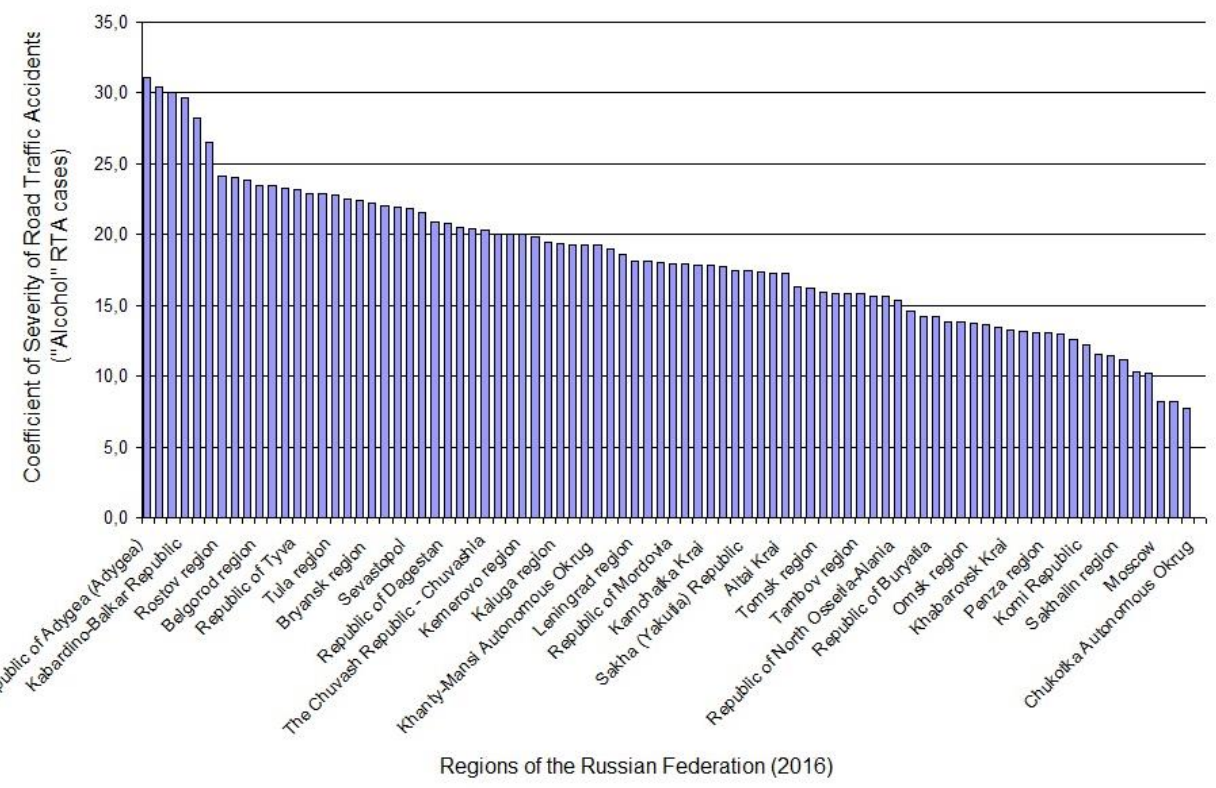

Fig. 2. Road accidents severity (road accidents that happened in the alcohol intoxication state) in different regions of Russian Federation in 2016 


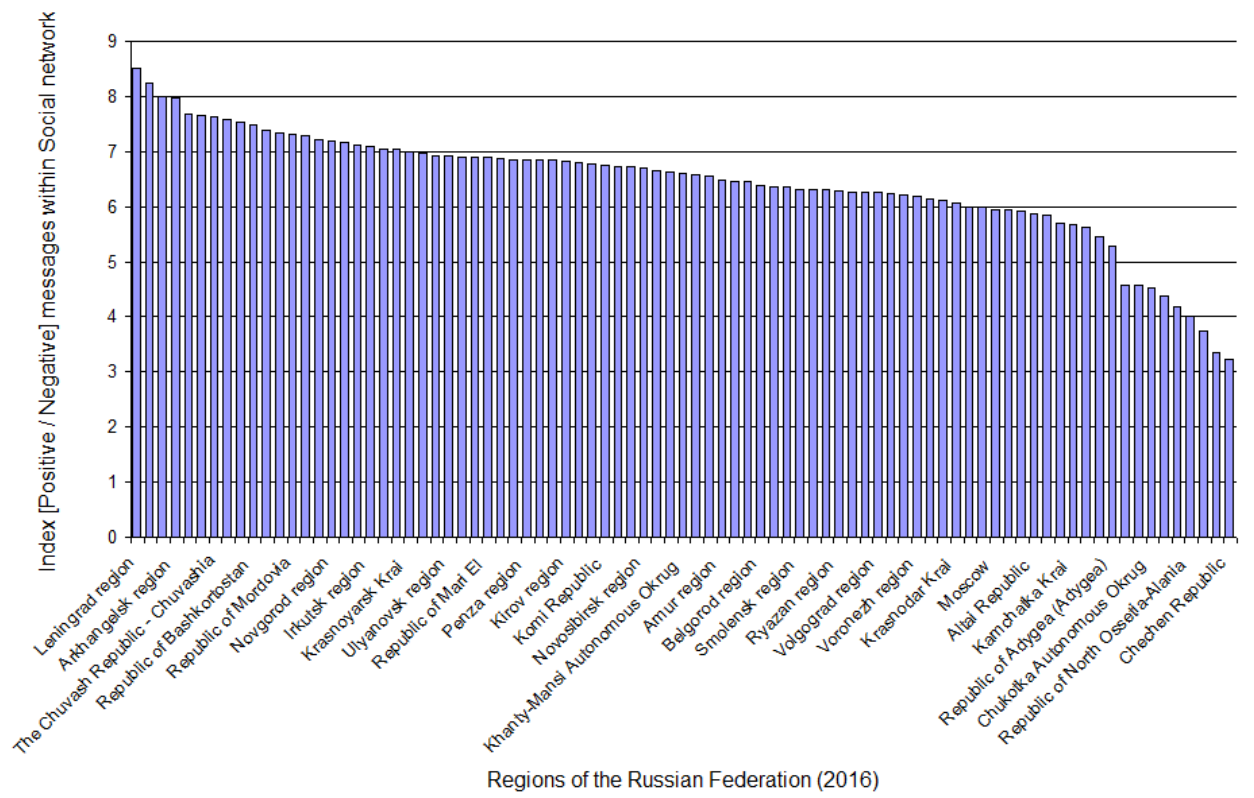

Fig. 3. Index of social health (Index of love) in different regions of Russian Federation in 2016 (according to the data of Brand Analytics [6])

\subsection{Establishment of the regularities of the impact of the psychoemotional state of the Russian regions' population on the road accidents severity}

On the basis of the data presented in the fig. 1...2 (road accidents severity in different Russian regions) ranked distributions of this indicator were built. Using the data on the ranked distribution of road accidents severity and the data on Index of social health, regression models Road accidents severity $=f$ (Index of social health) were defined in the fig. 4. Table 1 shows statistical characteristics of these models.

Table 1. Models Road accidents severity $=f($ Index of social health $)$ and its statistical characteristics

\begin{tabular}{|c|c|c|c|c|}
\hline Considered case & Model & $\mathrm{R}^{2}$ & $\mathrm{~F}$ & $\varepsilon, \%$ \\
\hline All road accidents (RTA) & $\mathrm{Y}=26.2159-2.7056 \cdot \mathrm{X}$ & 0.971 & 2735.2 & 0.178 \\
\hline $\begin{array}{c}\text { Road accidents that happened } \\
\text { in the alcohol intoxication state } \\
\text { («Alcohol» cases of RTA) }\end{array}$ & $\mathrm{Y}=50.3094-5.0231 \cdot \mathrm{X}$ & 0.911 & 856.6 & 1.63 \\
\hline
\end{tabular}

\subsection{Establishment of the regularities of the degree of the impact of the psychoemotional state of the Russian regions' population on the road accidents severity}

Figure 5 shows combined graphic of models Road accidents severity $=f$ (Index of social health) that were presented in the fig. 4. 


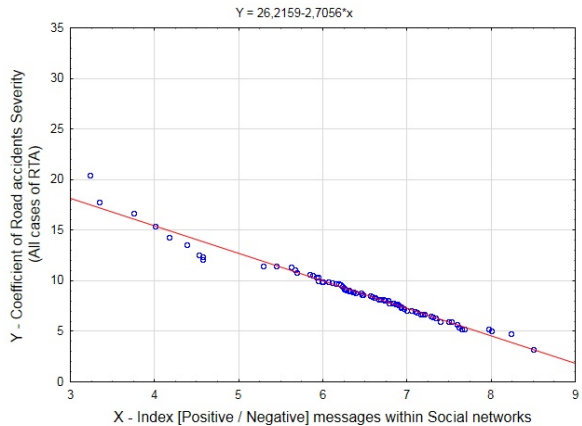

A). All road accidents (RTA)

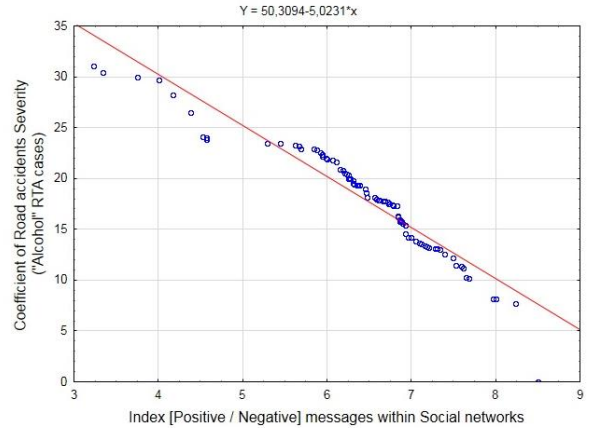

B). Road accidents that happened in the alcohol intoxication state («Alcohol» cases of RTA)

Fig. 4. Comparison of the graphs of the models Road accidents severity $=f($ Index of social health $)$

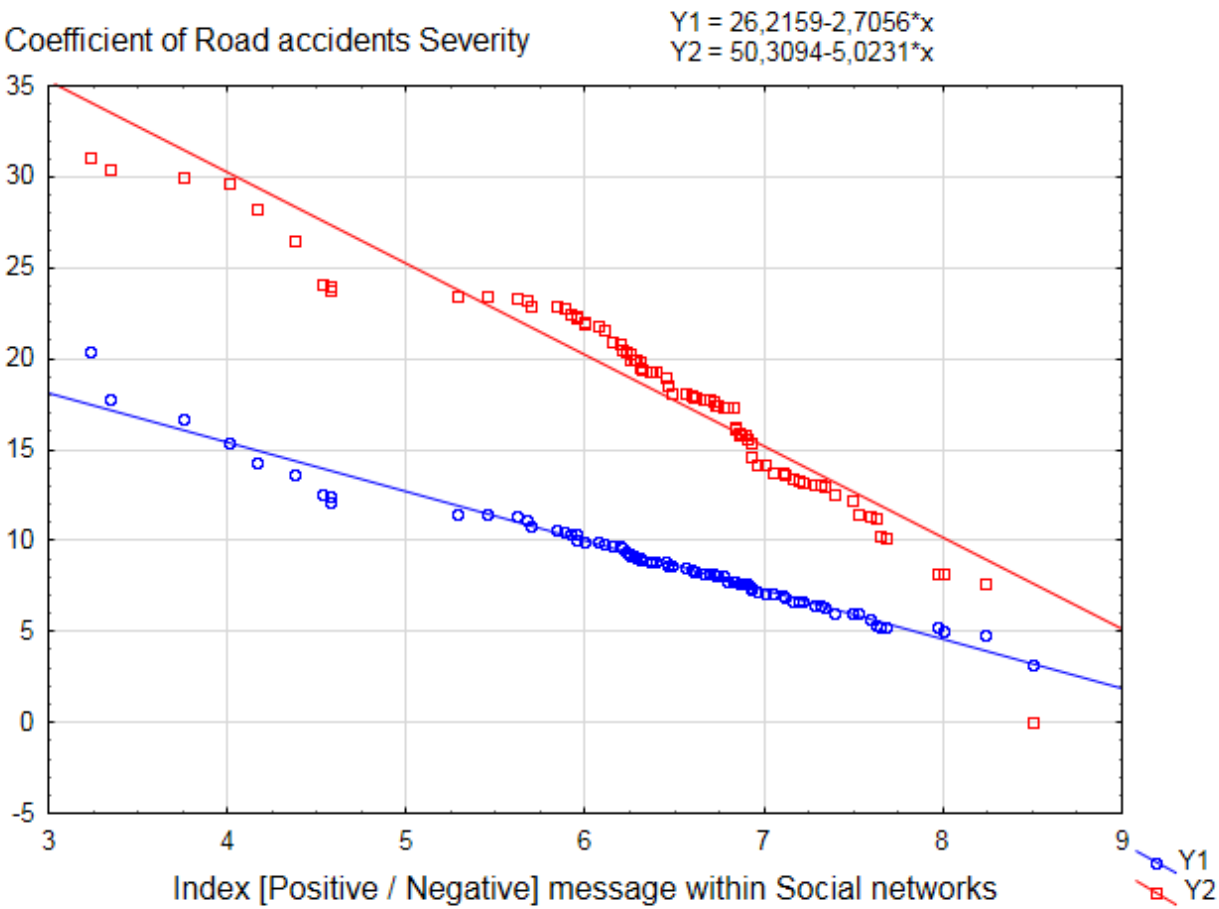

QY1 - All cases of RTA

४ Y2 - "Alcohol" cases of RTA

Fig. 5. Difference between models Road accidents severity $=f$ (Index of social health)

for cases «All road accidents» and «Road accidents that happened in the alcohol intoxication state» The cosine of the angle between straight lines that are respective to linear models $\mathrm{Y}=26.2159-2.7056 \cdot \mathrm{X}$ and $\mathrm{Y}=50.3094-5.0231 \cdot \mathrm{X}$ equals 0.9878 , it means that angle between them equals to $9^{\circ}$. This angle identifies the degree of difference between subjects 
of Russian Federation relatively to the impact of the psychoemotional state of different regions population on the road accidents severity.

Dependencies of fig. 5 show that with the worsening of society's psychoemotional background the general road accidents severity starts increasing but even more starts increasing the severity of road accidents that happened in the alcohol intoxication state.

\section{Conclusions}

According to the results of the research, presented in the context of this article, it is worth noting main conclusions:

1. The driver, his skills and his adaptability to the stress remain the main factors of road accident rate formation $[16,17]$.

2. The socioemotional atmosphere has a significant impact on the driver's psychological state. This fact is reflected in his everyday behavior, including extreme situations.

3. Research showed that significant difference in road accidents severity between Russian regions in many ways is defined by the psychoemotional state of society.

4. The socioemotional background of the region was measured by the technology of Big Data. The research that was carried out by the company Brand Analytics allowed identifying significant differences of psychoemotional background in different regions of Russian Federation. Analysis of official statistical data of road accidents rate (source - The General Administration for Traffic Safety of the Ministry of Internal Affairs of Russia) allowed building regression models of the relation between the psychoemotional state in regions and road accidents severity.

5. The research was carried out on the basis of two data sets: «All road accidents» and «Road accidents that happened in the alcohol intoxication state». It was established that with the worsening of psychoemotional background the road accidents severity increased. Especially it is evident in the case of road accidents that happened in the alcohol intoxication state.

6. Results of this research can be used in the development of regional programs of road safety management considering features of psychoemotional background in different subjects of Russian Federation.

Finally, unfortunately, Russian regional specificity practically isn't taking into account during the process of the development of road safety improvement federal programs. Meanwhile, a wide variety of means of transport exploitation conditions, cultural differences and psychological types in multiple Russian regions, especially national, demands differentiated approaches to road safety management. That can be achieved by usage of the psychosocial technologies or by correction of used approaches to the road safety monitoring considering national customs, population traditions that form transport culture.

\section{Reference}

1. A. I. Petrov, Features of formation of motor transportation accident rate in space and time (2015)

2. A. I. Petrov, Economic and social changes: facts, trends, forecast. 3(45) 154-172 (2016)

3. A.L. Zhuravlev, A.V. Yurevich, Economic science of modern Russia. 2(57): 137-140 (2012). 
4. A.V. Yurevich, M.A. Yurevich, Dynamics of psychological state of the Russian society: expert assessment / Morality of modern Russian society: psychological analysis: 21-41: (2012)

5. Brand Analytics company. Available from: https://br-analytics.ru/ [Accessed 6th June 2018]

6. URL: http://blog.br-analytics.ru/indeks-lyubvi-062016/ [Accessed 6th June 2018]

7. URL: http://stat.gibdd.ru/ [Accessed 8th June 2018]

8. Yu. A. Zubok, V.I. Chuprov, Economic and social changes: facts, tendencies, forecast. 10(1): 41-57 (2017)

9. Yu. Zubok, Economic and social changes: facts, tendencies, forecast 10(3) 32-40 (2017)

10. E. Petridou, M. Moustaki, European Journal of Epidemiology. 16(9) 819-826 (2000)

11. J. C. Stutts, D. W. Reinfurt, E. A. Rodgman, The role of driver distraction in crashes: an analysis of 1995-1999 Crashworthiness Data System Data. Annu Proc Assoc Adv Automot Med. 45: 287-301 (2001).

12. J. C. Stutts, D. W. Reinfurt, L. Staplin, et al., The role of driver distraction in traffic crashes (2001)

13. P. A. Pegin, Increase of the motor transport efficiency and safety on the basis of increase in capacity of highways. PhD Thesis Dr.Sci.Tech. (2011)

14. P. A. Pegin, Motor transportation psychology (2014)

15. N. Romanov, P. A. Pegin, Reliability of the driver (2006)

16. V. Kolesov, A. Petrov, Transportation Research Procedia. 20 305-310 (2017)

17. P. Kravchenko, E. Oleshchenko, Transportation Research Procedia. 20 367-372 (2017) 